\title{
Concerted Metal Cation Desorption and Proton Transfer on Deprotonated Silica Surfaces
}

\author{
Kevin Leung*, Louise J. Criscenti, Andrew W. Knight, \\ Anastasia G. Ilgen, Tuan A. Ho, and Jeffery A. Greathouse \\ Sandia National Laboratories, MS 1415, \\ E6 0754 , Albuquerque, NM 87185 \\ *kleung@sandia.gov
}

(Dated: November 2, 2018)

\begin{abstract}
The adsorption equilibrium constants of monovalent and divalent cations to material surfaces in aqueous media are central to many technological, natural, and geochemical processes. Cation adsorption/desorption is often proposed to occur in concert with proton-transfer on hydroxylcovered mineral surfaces, but so far this cooperative effect has been inferred indirectly. This work applies Density Functional Theory (DFT)-based molecular dynamics simulations of explicit liquid water/mineral interfaces to calculate metal ion desorption free energies. Monodentate adsorption of $\mathrm{Na}^{+}, \mathrm{Mg}^{2+}$, and $\mathrm{Cu}^{2+}$ on partially deprotonated silica surfaces are considered. $\mathrm{Na}^{+}$is predicted to be unbound, while $\mathrm{Cu}^{2+}$ exhibits larger binding free energies to surface $\mathrm{SiO}^{-}$groups than $\mathrm{Mg}^{2+}$. The predicted trends agree with competitive adsorption measurements on fumed silica surfaces. As desorption proceeds, $\mathrm{Cu}^{2+}$ dissociates one of the $\mathrm{H}_{2} \mathrm{O}$ molecules in its first solvation shell, turning into $\mathrm{Cu}^{2+}\left(\mathrm{OH}^{-}\right)\left(\mathrm{H}_{2} \mathrm{O}\right)_{3}$, while $\mathrm{Mg}$ remains $\mathrm{Mg}^{2+}\left(\mathrm{H}_{2} \mathrm{O}\right)_{6}$. The protonation state of the $\mathrm{SiO}^{-}$group at the initial binding site does not vary monotonically with cation desorption.
\end{abstract}


The adsorption free energies of ions on to material surfaces in liquid media govern equilibrium constants and adsorption isotherms, which are central to many technological and geochemical processes. ${ }^{1-5}$ One key aspect of interfaces between aqueous electrolyte and materials interface, distinct from those of aprotic solvents, is the possibility of acid-base reactions occurring in conjunction with ion adsorption. Surface hydroxyl (-OH) groups, ubiquitous at water interfaces, can release $\mathrm{H}^{+}$as cations adsorbs, especially for multivalent cations. $\mathrm{OH}^{-}$can also be released as oxyanions bind to the surface. $\frac{4}{\underline{4}}$ This phenomenon is well known in geochemistry contexts,,$\underline{\underline{6}} \underline{\underline{8}}$ but its occurrence is generally inferred indirectly from measurements or estimated from continuum models. Computationally, it has been shown that divalent cation binding energies at water-oxide interface can differ by a very large amount $\sim 2 \mathrm{eV}(46 \mathrm{kcal} / \mathrm{mol})^{\frac{9}{\underline{T}}}$ - depending on whether surface $\mathrm{OH}$ groups are deprotonated or not. But the computational method used there, and in most existing molecular calculations, does not permit spontaneous, simultaneous deprotonation and cation adsorption events. It begs the question of what quantitative effect allowing such cooperative behavior would make. Benchmark calculations are urgently needed.

Apart from this cooperativity, understanding many aspects of cation adsorption remains challenging. Tremendous progress has been made via non-linear optical spectroscopy $\underline{8}$ nuclear magnetic nesonance (NMR) 10 X-ray photoelectron spectroscopy and other X-ray methods, $\stackrel{4,11}{1} \underline{12}$ titration,$\underline{13}$ batch adsorption, $\stackrel{14,15}{\underline{1}}$ and calorimetry techniques 16 to investigate cation adsorption, including on silica surfaces which are ubiquitous in many applications and areas of science. But disagreements about fundamental aspects, such as whether cations are adsorbed in outer- $-\underline{8,10}$ or inner-sphere ${ }^{16}$ configurations, have persisted. Here inner-sphere means direct contact between $\mathrm{SiO}^{-} / \mathrm{M}^{+}$, while outer-sphere is water-mediated adsorption, $\mathrm{SiO}^{-} / \mathrm{H}_{2} \mathrm{O} / \mathrm{M}^{+}$.

Atomic length-scale modeling can shed light on many aspects of cation adsorption. $\underline{9}, 17-20$ In particular, force field-based potential-of-mean-force (PMF) calculations have been successfully applied to study divalent metal cations desorption from mineral surfaces. 9.18 However, it is challenging to use non-electronic structure methods to model the interactions between transition metal (TM) cations and ligands $\underline{\underline{7}}^{-}$This is because TM ions with partially filled $3 d$ orbitals are difficult to parameterize with molecular force fields. Furthermore, with few exceptions, $\stackrel{21}{2-23}$ most existing force fields for minerals do not permit dynamical changes in the protonation states in the ubiquitous hydroxyl groups on mineral surfaces. Molecular 
dynamics studies have generally resorted to static assignment of surface hydroxyl deprotonation states. This approach cannot address correlations and dynamical fluctuations in the electrostatic environments of binding sites due to acid-base reactions.

The present work highlights the coupled cation desorption/material surface proton transfer phenomenon, using Density Functional Theory (DFT)-based molecular dynamics (or " $a b$ initio molecular dynamics" / AIMD) simulations. AIMD has been shown to predict acid-base reactions to within $1 \mathrm{pH}$ unit. ${ }^{24}-35$ DFT also explicitly includes the effect of partial $3 d$ orbital occupancies. AIMD is therefore well-suited to modeling metal adsorption on mineral

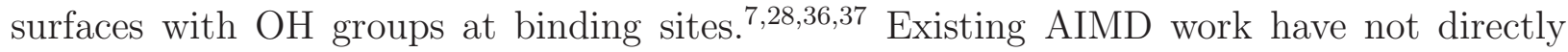
addressed cooperative acid-base/cation adsorption, partly because some materials surfaces previously examined may not exhibit this behavior and partly because PMF methods have not been applied to pull cations sufficiently far from the surface. Our AIMD results will be supported by batch adsorption isotherm experiments and compared with classical force field predictions.

The cations of interest here are $\mathrm{Na}^{+}, \mathrm{Mg}^{2+}$, and $\mathrm{Cu}^{2+}$. The model substrate chosen is a reconstructed $\beta$-crystabolite (001) surface, with about $4 / \mathrm{nm}^{2}$ SiOH group surface density $\underline{\underline{33}}$ It has several advantages as a benchmark. (1) The surface $\mathrm{SiOH}$ density is in reasonable accord with that cited for well-soaked, amorphous silica. $\underline{38}$ (2) We have previously computed its $\mathrm{pK}_{a}$ using AIMD potential-of-mean-force calculations, and can therefore correlate this $\mathrm{pK}_{a}$ with cation desorption calculations conducted using similar AIMD methods. (3) The surface has a moderate cell size, and only one distinct type of silanol ( $\mathrm{SiOH})$ group. Each $\mathrm{SiOH}$ is at least $5 \AA$ from all other $\mathrm{SiOH}$, ensuring that cations can only coordinate to one $\mathrm{SiO}^{-}$group on this model surface (i.e., they are monodentate). This feature simplifies the computational analysis. In contrast, many crystalline mineral surfaces feature numerous cation-binding sites and types of hydroxyl groups. ${ }^{7}$

Finite temperature AIMD simulations apply the Perdew-Burke-Ernzerhof (PBE) functional, ${ }^{39}$ the projector-augmented wave-based Vienna Atomic Simulation Package (VASP), $\stackrel{40,41}{\Perp}$ a $400 \mathrm{eV}$ energy cutoff, and $\Gamma$-point sampling of the Brillouin zone. All simulation cells have dimensions $10.12 \AA \times 10.12 \AA \times 26.0 \AA$. These settings are similar to those in our previous $\mathrm{pK}_{a}$ work. ${ }^{33}, \underline{34}$ Spin-polarized DFT calculations, with one net unpaired electron, are conducted when $\mathrm{Cu}^{2+}$ is present. The $\mathrm{Cu}$ pseudopotential used does not include pseudovalent $3 p$ electrons. To keep the simulation cells charge neutral, one or two $\mathrm{H}^{+}$are removed 
from the silica surface with an adsorbed cation. One of the resulting $\mathrm{SiO}^{-}$is initially coordinated to the $\mathrm{M}^{n+}$. The overall stoichiometries are $\mathrm{Si}_{20} \mathrm{O}_{107} \mathrm{H}_{133}{ }^{-} \mathrm{Na}^{+}$and $\mathrm{Si}_{20} \mathrm{O}_{108} \mathrm{H}_{134}^{-} \mathrm{M}^{2+}$. For details of the initiation of AIMD simulation cells, see the Supporting Information (S.I.) document.

In the presence of acid functional groups at water/material interfaces, the $\mathrm{pH}$ in the simulation cell should be pinned at the $\mathrm{pK}_{a}$ of functional groups, provided that (1) there is only one type of such groups; (2) a fraction of them are deprotonated; (3) their $\mathrm{pK}_{a}$ is lower than that of $\mathrm{H}_{2} \mathrm{O}$; and (4) the surface groups do not interact with each other. Within the non-interacting assumption, the $\mathrm{pH}$ in our AIMD cells should be between 7.0 and 8.1 - the $\mathrm{pK}_{a}$ range previously predicted for this surface.$^{33}$ In experimental samples with amorphous or crystalline silica, bimodal or trimodal $\mathrm{pK}_{a}$ distributions of $\mathrm{pK}_{a}$ have been reported. $\underline{42,43}$ It would have been more challenging to assign $\mathrm{pK}_{a}$ in AIMD simulation cells with multiple types of $\mathrm{SiOH}$.

Potential-of-mean-force (PMF) free energy simulations computes $\Delta W(Z)$ as the natural logrithm of the probability distribution of the two-body reaction coordinate of the form $Z=z_{\mathrm{O}}-z_{\mathrm{M}}$ (S.I.). Here $Z$ is the coordinate normal to the silica-water interface, $\mathrm{M}$ is the desorbing cation, and $\mathrm{O}$ is part of the initially deprotonated surface $\mathrm{SiOH}$ group bound to $\mathrm{M}^{n+}$. The first window represents configurations with $\mathrm{M}^{n+}$ bound to the $\mathrm{SiO}^{-}$group; subsequent windows have $\mathrm{M}^{n+}$ progressively displaced farther away.

$\Delta W(Z)$ is effectively the constrained free energy at a $Z$ value; it includes neither fluctuations around $Z$ nor the standard state reference associated with aqueous solutions. To obtain the adsorption free energy $\left(\Delta G_{\text {ads }}\right)$ from $\Delta W(Z)$, we integrate configuration space in three dimensions, and account for the entropic contribution from a standard state $1.0 \mathrm{M}$ ideal concentration solution: ${ }^{44}$

$$
\Delta G_{\mathrm{ads}} / k_{\mathrm{B}} T=-\log \left\{\int_{\Omega} d \Omega \exp \left[-\Delta W(Z) / k_{\mathrm{B}} T\right] /\left(V_{o}\right)\right\} .
$$

Here $V_{o}$ is the volume associated with $1.0 \mathrm{M}$ aqueous solution $\left(1662 \AA^{3}\right)$ and $\mathrm{T}=300 \mathrm{~K}$ is assumed. The volume element $\Omega$ spans the configuration space where $\mathrm{M}^{n+}$ is "bonded" to the $\mathrm{SiO}^{-}$group. A limiting bonding distance of $2.50 \AA$ is assumed. At this separation the pair correlation functions between transition metal ions and water oxygen sites exhibits their first turning points. $\stackrel{45}{=}$ The angular distribution is also involved in the integral. To our knowledge, $\Omega$ has not been standardized for PMF calculations at interfaces. $\underline{9}, \underline{18}, \underline{37}$ Here we approximate it 


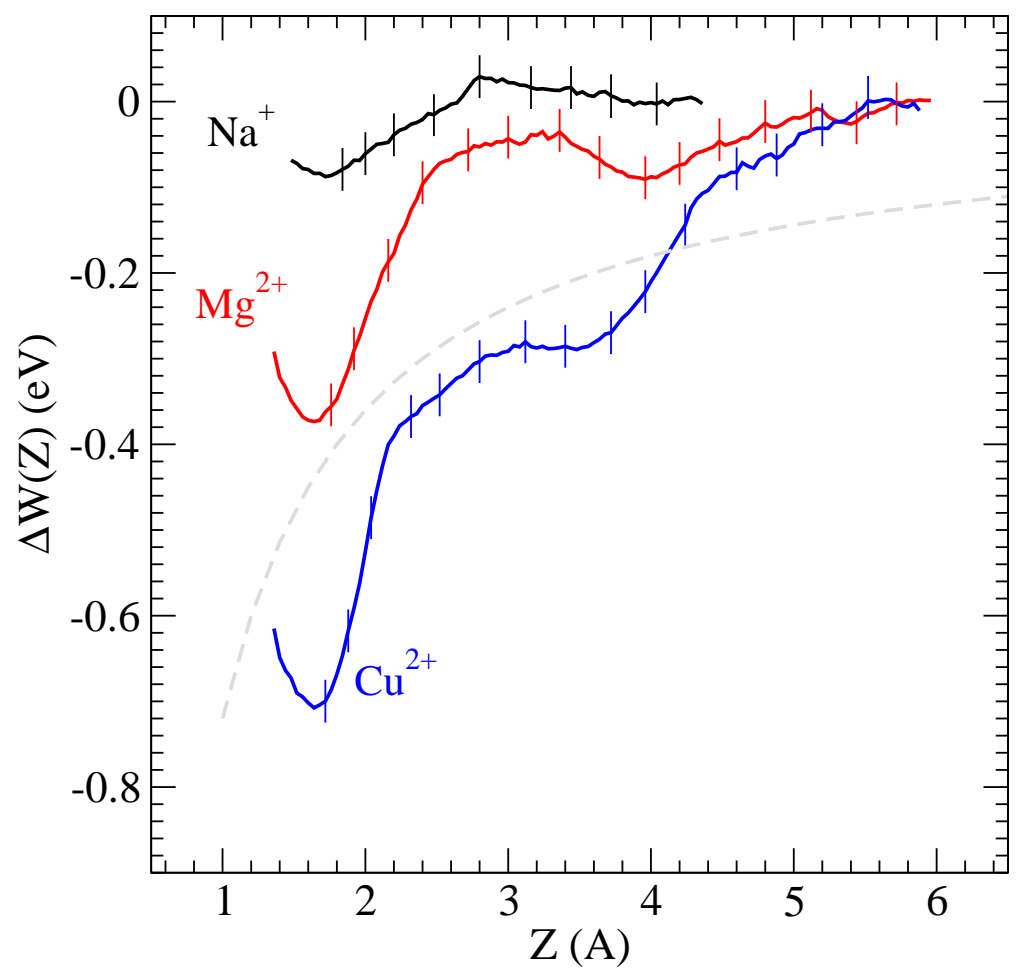

FIG. 1: Potential-of-mean-force (PMF) predictions of metal cation $\mathrm{M}^{n+}$ desorption profile $(\Delta W(Z))$ as a function of the vertical separation $(Z)$ between $\mathrm{Mn}^{n+}$ and the $\mathrm{O}$ atom of the $\mathrm{SiO}^{-}$group to which the cation is initially coordinated. Black, red, blue refer to $\mathrm{M}=\mathrm{Na}, \mathrm{Mg}$, and $\mathrm{Cu}$, respectively. Grey dashed line denotes the coulomb attaction between +2 and -2 charges screened by $\epsilon_{o}=78$. Vertical lines indicate the end points of sampling windows; they are not error bars.

as a cylinder with a radius $R=0.5 \AA$ estimated from a completely unconstrained trajectory. Electrostatic corrections associated with image dipoles are added to $\mathrm{Mg}^{2+} \mathrm{PMF}$ predictions. These corrections do not exceed $0.1 \mathrm{eV}$, are less than $0.03 \mathrm{eV}$ for monovalent cations, and are further discussed in the S.I.

Figure 1 depicts the potentials-of-mean-force associated with $\mathrm{Na}^{+}, \mathrm{Mg}^{2+}$, and $\mathrm{Cu}^{2+}$ desorption. The minima of $\Delta W(Z)$, relative to the asymptotic, large $Z$ regime, are $0.087 \pm 0.03 \mathrm{eV},-0.38 \pm 0.05 \mathrm{eV}$, and $-0.71 \pm 0.07$, respectively. The uncertainties reflect one standard deviation.

First we focus on $\mathrm{Na}^{+}$on reconstructed $\beta$-cristobalite surface, with one deprotonated 
$\mathrm{SiOH}$ group in the surface cell. In other words, $25 \%$ of the $\mathrm{SiOH}$ on one surface is deprotonated. Fig. 1 shows that the $\Delta W(Z)$ minimum is very shallow $(-0.087 \mathrm{eV})$ for $\mathrm{Na}^{+}$. We start an AIMD trajectory with $\mathrm{Na}^{+}$coordinated to the surface site, without applying constraints. $\mathrm{Na}^{+}$remains there for $\sim 45 \mathrm{ps}$; at longer times, it spontaneously escapes into the bulk solution. The statistics in Fig. 1 are collected prior to this spontaneous event. In subsequent sampling windows, PMF calculations circumvents this time scale problem by using constraining potentials. Substituting $\Delta W(Z)$ into Eq. 1, the free energy cost of $\mathrm{Na}^{+}$ adsorbing on to this silica surface from a $1.0 \mathrm{M} \mathrm{Na}^{+}$solution is $\Delta G_{\text {abs }}=+0.13 \mathrm{eV}$, if $\mathrm{Na}^{+}$is assumed to exhibit an activity coefficient of unity. The positive sign of $\Delta G_{\text {abs }}$ means there is no tendency for $\mathrm{Na}^{+}$to bind to the surface.

Fig. 2a-b depict configurations in trajectories constrained around $Z \sim 2.7 \AA$ and $3.0 \AA$, respectively. In both snapshots, the $\mathrm{SiO}^{-}$group originally coordinated to $\mathrm{Na}^{+}$has become protonated. An $\mathrm{H}_{2} \mathrm{O}$ molecule has spontaneously inserted between the $\mathrm{SiOH}$ group and the $\mathrm{Na}^{+}$before the second snapshot takes place. An apparent coordination number of four is seen in these snapshots only because the $\mathrm{Na}^{+}$is close to the surface. In the $Z \sim 4.2 \AA$ window, we have computed the pair correlation $g(r)$ between $\mathrm{Na}^{+}$and $\mathrm{H}_{2} \mathrm{O} \mathrm{O}$ atoms. The first minimum in the $g(r)$ is $\sim 3.16 \AA$; integrating to this distance yields an average hydration number of 5.17. These values are similar to those computed for $\mathrm{Na}^{+}$in bulk water using $\mathrm{AIMD}^{46}$ and polarizable force field $\underline{47}$ methods.

A recent calorimetry study reports favorable inner-sphere $\mathrm{Na}^{+}$adsorption enthalpy on partially deprotonated quartz particle surfaces at $\mathrm{pH}=4 . \underline{16}$ Relating the quantitative enthalpic value per milligram silica sample to our calculations is challenging because the surface densities per type of deprotonated $\mathrm{SiOH}$ groups per unit surface area are not specified. $\mathrm{Na}^{+}$adsorption on silica has been inferred as inner-sphere ${ }^{16}$ or outer-sphere, 10 depending on the measurement technique used, although the details of the silica samples and electrolytes differ. Our prediction that $\mathrm{Na}^{+}$is unbound on a specific model silica surface beyond a $\sim 45$ ps residence time may help interpret the data and resolve the discrepancy.

Recent AIMD simulations of deprotonated silica surfaces 27,35 have reported persistent $\mathrm{Na}^{+}$coordination to the quartz (001) surface for the duration of trajectory lengths of $\sim 10$ ps. However, that surface exhibits a higher $\mathrm{SiOH}$ surface density than our model or amorphous silica. $\mathrm{Na}^{+}$can be also be bidentate or even tridentate on quartz (001). Future AIMD calculations to compute desorption PMF associated with $\mathrm{Na}^{+}$at bidentate sites will further 
clarify transient inner- versus outer-sphere adsorption behavior.

We have also performed classical MD simulations using the same AIMD cristobalite surface, but increasing the surface area by a factor of four and adding a thicker aqueous layer $(30 \AA)$. Adsorption properties are obtained from unconstrained and umbrella sampling simulations. Final snapshots reveal that the $\mathrm{Na}^{+}$moves away from the $\mathrm{SiO}^{-}$site and forms an inner-sphere monodentate complex with a neutral $\mathrm{SiOH}$ site. This is qualitatively similar to ReaxFF predictions. $\frac{23}{=}$ Although the classical $\mathrm{MD} \mathrm{Na}^{+} / \mathrm{SiO}^{-}$interactions have not yet been fitted to DFT/AIMD predictions and differ from AIMD simulations in the binding site configuration, the classical $\Delta W(Z)$ is qualitatively similar (Fig. S3 in the S.I.).

The first minimum in the $\mathrm{Mg}^{2+} \Delta W(Z)$, at $-0.37 \mathrm{eV}$, is located at $\sim 1.68 \AA$ (Fig. 1). A weak second minimum at $3.96 \AA$ yields a $-0.09 \mathrm{eV}$ attraction, separated by a small barrier at $3.36 \AA$. This second valley represents an outer-sphere complex. In all configurations examined, $\mathrm{Mg}^{2+}$ is octahedrally coordinated to either $5 \mathrm{H}_{2} \mathrm{O}$ molecules and one $\mathrm{SiO}^{-}$group (Fig. 2r) or $6 \mathrm{H}_{2} \mathrm{O}$ molecules (Fig. 2d). Integrating $\Delta W(Z)$ via Eq. 1 yields a favorable $0.14 \mathrm{eV}$ binding free energy, unlike $\mathrm{Na}^{+}$which is predicted to be unbound. Calorimetry studies has shown that $\mathrm{Mg}^{2+}$ adsorption yields larger enthapy release than $\mathrm{Na}^{+} \underline{\underline{16}}$ Reference 8 has estimated a small $0.30 \mathrm{eV}$ binding free energy between $\mathrm{Mg}^{2+}$ and silica surfaces, although it interprets the coordination as outer-sphere.

The grey dashed line depicts the coulombic attraction between \pm 2 charges screened by $1 / \epsilon_{o}$ appropriate to liquid water. The $\Delta W(Z)$ curve for $\mathrm{Mg}^{2+}$ does not exhibit such asymptotic behavior. Other classical force field-based PMF calculations with charged mineral surfaces and larger simulation cells than AIMD simulations also reach a plateau for $Z \sim 6 \AA$; see Ref. 9 and Fig. S3 in this work. Hence the $\mathrm{Mg}^{2+}$ plateau in Fig. 1 does not appear related to finite size effects associated with AIMD simulation cells.

Fig. 1 also depicts the $\Delta W(Z)$ associated with $\mathrm{Cu}^{2+}$. Substituting the relevant $\Delta W(Z)$ into Eq.1, the $\mathrm{Cu}^{2+}$ adsorption free energy is found to be a favorable $-0.47 \mathrm{eV}$. This is substantially higher than our predicted $\mathrm{Mg}^{2+}$ value. It is a general trend that first row transition metal divalent cations tend to exhibit stronger binding behavior $\underline{\underline{53}}$ In the $\mathrm{SiO}^{-}$$\mathrm{Cu}^{2+}$ inner-sphere complex regime (Fig. 2 ) $), \mathrm{Cu}^{2+}$ is coordinated to $4 \mathrm{H}_{2} \mathrm{O}$ and a $\mathrm{SiO}^{-}$ group, which is slightly different from the 6-coordinated $\mathrm{Mg}^{2+}$ (Fig. $2 \mathrm{~d}$ ). Indeed, even in liquid water, it has been reported that the inner solvation shell of $\mathrm{Cu}^{2+}$ exhibits first hydration shell behaviors distinct from other first row transition metal ions. $\underline{11}, 45$ 


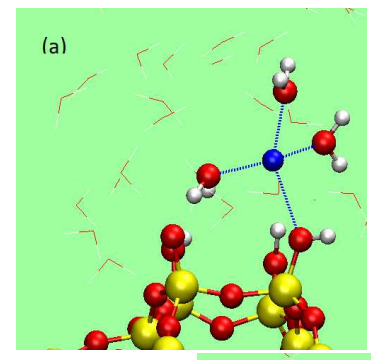

(e)

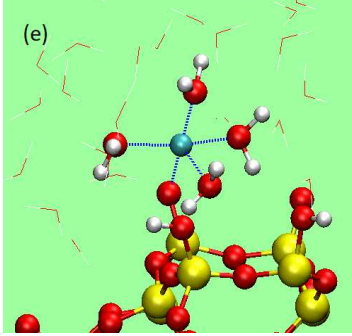

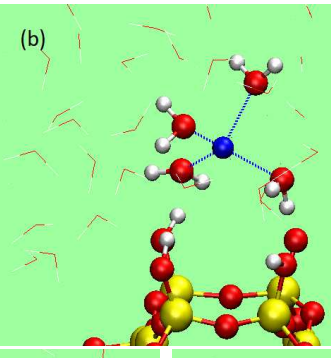

(f)
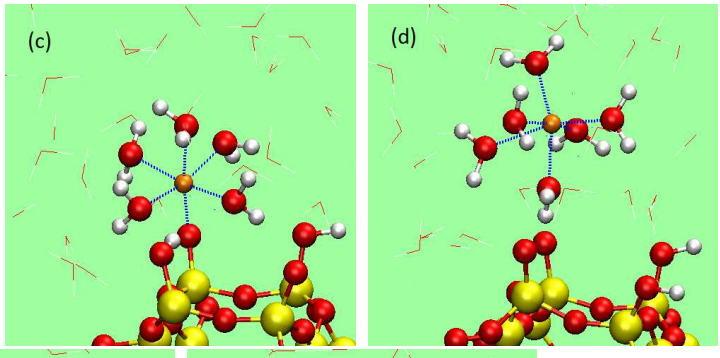

(g)
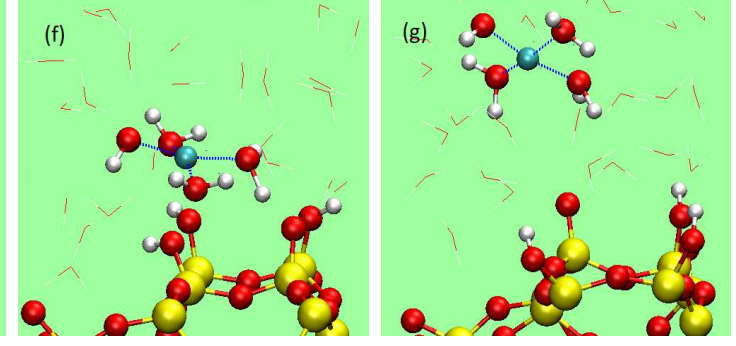

FIG. 2: Snapshots of (a)-(b) $\mathrm{Na}^{+}, Z \sim 2.7 \AA$, and $3.0 \AA$; (c) $\mathrm{Mg}^{2+}, Z \sim 1.6 \AA$ (unconstrained in $Z$ direction); (d) $\mathrm{Mg}^{2+}, Z \sim 3.8 \AA$; (e) $\mathrm{Cu}^{2+}, Z \sim 1.6 \AA$; (f) $\mathrm{Cu}^{2+}, Z \sim 2.7 \AA$; (g) $\mathrm{Cu}^{2+}, Z \sim 4.5 \AA$. $\mathrm{Na}, \mathrm{Mg}, \mathrm{Cu}, \mathrm{Si}, \mathrm{O}$, and $\mathrm{H}$ atoms are colored in blue, orange, cyan, yellow, red, and white. $\mathrm{H}_{2} \mathrm{O}$ are thin lines, except that those coordinated to the cation are depicted as ball-and-stick models. Thicker lines depict $\mathrm{SiO}-\mathrm{H}$ bonds. $\mathrm{No} \mathrm{OH}^{-}$is coordinated to the cations in panels (a)-(e), but a $\mathrm{OH}^{-}$clearly appears on $\mathrm{Cu}^{2+}$ in $(\mathrm{f})-(\mathrm{g})$.

Away from the $Z>2 \AA$ regime, our AIMD simulations consistently predict that $\mathrm{Cu}^{2+}$ exists as a square-planar $\mathrm{Cu}^{2+}\left(\mathrm{OH}^{-}\right)\left(\mathrm{H}_{2} \mathrm{O}\right)_{3}$ instead of an octahedral $\mathrm{Cu}^{2+}\left(\mathrm{H}_{2} \mathrm{O}\right)_{6}$ (Fig. 2fg). The $\mathrm{OH}^{-}$originates from an $\mathrm{H}_{2} \mathrm{O}$ molecule directly coordinated to $\mathrm{Cu}^{2+}$ which has lost a $\mathrm{H}^{+}$to one of the two $\mathrm{SiO}^{-}$groups initially on the surface when $Z$ is small. This $\mathrm{H}_{2} \mathrm{O}$ deprotonation event changes the $\mathrm{Cu}^{2+}$ coordination number drastically.

We have not applied AIMD to calculate the $\mathrm{pK}_{a}$ associated with $\mathrm{H}_{2} \mathrm{O}$ moecules bonded to $\mathrm{Cu}^{2+}$. But experimental $\mathrm{pK}_{a}$ of water in the $\mathrm{M}^{2+}\left(\mathrm{H}_{2} \mathrm{O}\right)_{6}$ first solvation shell have been quoted as 8 and 11.2-11.4 for $\mathrm{Cu}^{2+}$ and $\mathrm{Mg}^{2+}$, respectively. ${ }^{50}, 51$ Similar trends have been predicted in cluster-based DFT calculations. ${ }^{52}$ The silanol deprotonation $\mathrm{pK}_{a}$ for this reconstructed $\beta$ cristobalite surface has been predicted to be 7.0-8.1. $\stackrel{33}{\text { So the }} \mathrm{pK}_{a}$ of $\mathrm{SiOH}$ and $\mathrm{Cu}^{2+}\left(\mathrm{H}_{2} \mathrm{O}\right)_{6}$ are very similar. The fact that the simulation cell contains a fraction of deprotonated $\mathrm{SiOH}$ means that the solution $\mathrm{pH}$ is pinned at the $\mathrm{SiOH} \mathrm{pK}_{a}$ value. It is therefore reasonable that we observe deprotonation of $\mathrm{Cu}^{2+}\left(\mathrm{H}_{2} \mathrm{O}\right)_{n}$ but not of $\mathrm{Mg}^{2+}\left(\mathrm{H}_{2} \mathrm{O}\right)_{6}$. A lower $\mathrm{pK}_{a}$ in the first hydration shell has been linked to stronger tendency towards metal cation adsorption 
or precipitation $\stackrel{14}{\underline{4}}$ Experimentally, $\mathrm{SiOH} \mathrm{pK}_{a}$ has been proposed to follow bimodal $\stackrel{42}{2}$ or even trimodal $\frac{43}{\underline{3}}$ distributions. If $\mathrm{Cu}^{2+}$ is desorbed from a $\mathrm{SiO}^{-}$group with $\mathrm{pK}_{a}=4.5 \stackrel{42}{\underline{42}}$ the $\mathrm{Cu}^{2+}\left(\mathrm{H}_{2} \mathrm{O}\right)_{n}$ complex would be insufficiently acidic to protonate the $\mathrm{SiO}^{-}$group. So far, at atomic length-scale, such low $\mathrm{pK}_{a} \mathrm{SiOH}$ groups have been identified only on quartz (0001) or amorphous silica surfaces,$\underline{26}-\underline{28}$ or as transient species $\underline{\underline{33}}$

In addition to the deprotonation of a $\mathrm{H}_{2} \mathrm{O}$ coordinated to $\mathrm{Cu}^{2+}$, AIMD simulations of all three cations involve proton exchange between neighboring $\mathrm{SiO}^{-}$and $\mathrm{SiOH}$ groups on the same surface via water bridges once the cations are sufficiently far away from the surface. This will be further discussed below (Fig. 4).

In Fig. S3, classical force field MD simulations also yield a larger $\mathrm{Cu}^{2+}$ desorption free energy than $\mathrm{Mg}^{2+}$. This is qualitatively consistent with AIMD results, although the magnitude of the inner-shell minimum in $\Delta W(Z)$ is overestimated compared to AIMD predictions, just as it is for $\mathrm{Mg}^{2+}$. A separate simulation was performed with a hydroxide ion added to the $\mathrm{Cu}^{2+}$ system. The hydroxide ion remains in the first coordination shell of $\mathrm{Cu}^{2+}$, but the $\mathrm{Cu}^{2+}$ coordination changes from 6-fold to 5 -fold when the hydroxide ion is present. The $\Delta W(Z)$ for both ions are predicted to be qualitatively similar but with larger $\mathrm{Cu}^{2+}$ innershell solvation free energy. It cannot be ruled out that part of the overestimate lies in the inability of classical force field used to adequately describe cooperative acid-base behavior. Fine-tuning of the force field will be conducted in the future.

There are few AIMD simulations of $\mathrm{Cu}^{2+}$ on oxide surfaces, but predictions about other transition metal ions make useful comparisons. Ref. 37 applies AIMD simulations to show that removing $\mathrm{Ni}^{2+}$ from $\mathrm{SiOH}$ groups at clay edges requires a significant $0.69 \mathrm{eV}$ to reach the first barrier at $\sim 3 \AA$. This $0.69 \mathrm{eV}$ free energy change is likely associated with an outer-sphere configuration rather than infinite separation between $\mathrm{Ni}^{2+}$ and the clay substrate. $\mathrm{Cd}^{2+}$ is predicted to exhibit a smaller, but still significant $0.23 \mathrm{eV}$ initial barrier towards desorption.$\underline{36}$ Using classical force field-based molecular dynamics, Ref. 9 models $\mathrm{Fe}^{2+}$ desorption from both charge-neutral and deprotonated hematite (001) surfaces. While a quantative comparison with our charged surface should not be made, the PMF reported there for the neutral surface has less structure in $\Delta W(z)$ beyond $z=4 \AA$ than in the $\mathrm{Mg}^{2+}$ PMF in Ref. 18 regardless of the force field used. The charged surface with a $\left(\mathrm{SiO}^{-}\right)_{2} \mathrm{Fe}$ (II) binding site exhibits $\sim 1.7-2.2 \mathrm{eV}$ first minima in $\Delta W(Z)$. We stress that none of the calculations discussed for this comparison purpose have reported cooperative acid-base reactions 


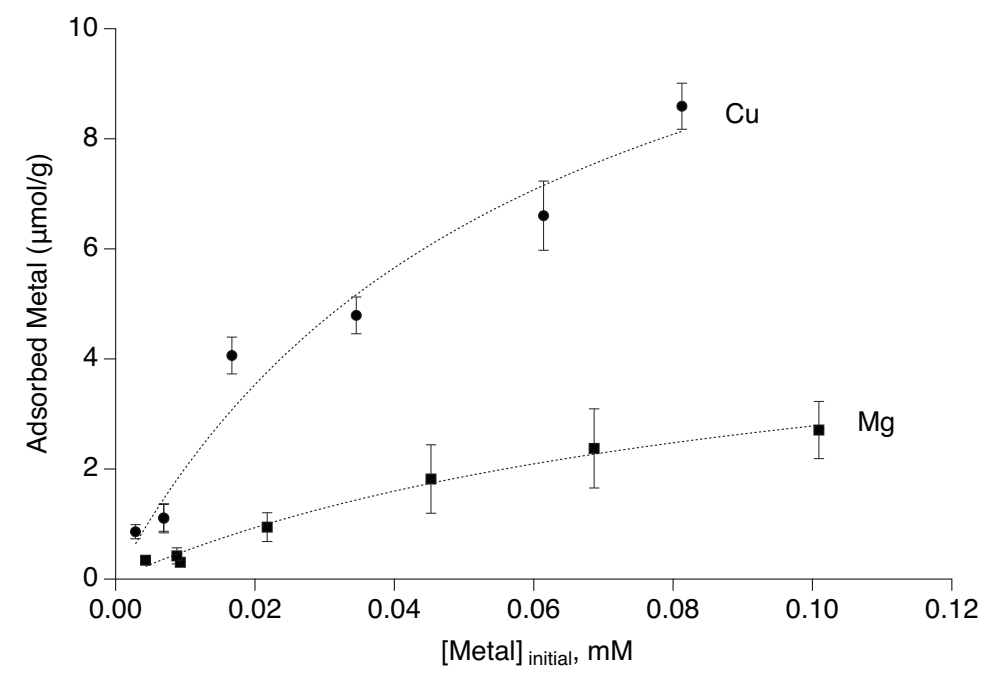

FIG. 3: Competitive batch adsorption measurements showing that $\mathrm{Cu}^{2+}$ adsorbs more readily than $\mathrm{Mg}^{2+}$ on fumed silica surfaces at different electrolyte concentrations.

- either because they apply classical force fields or because the material surface is different.

On amorphous silica surfaces, $\mathrm{Cu}^{2+}$ can form dimers. ${ }^{12}$ At sufficiently high $\mathrm{pH}$ it precipitates to form $\mathrm{Cu}(\mathrm{OH})_{2}$. Our AIMD simulation cells, which contain one divalent cation, cannot model dimerization and precipitation. However, the intriguing desorption configurations we predict are likely precursors to such complex $\mathrm{Cu}^{2+}$ behavior if more than one $\mathrm{Cu}^{2+}$ is present.

Batch adsorption isotherm experiments were performed to evaluate the competitive adsorption of $\mathrm{Cu}$ and $\mathrm{Mg}$ on fumed silica and provide validation of DFT calculations. For competitive adsorption studies, $\mathrm{Cu}\left(\mathrm{NO}_{3}\right)_{2}$ and $\mathrm{Mg}\left(\mathrm{NO}_{3}\right)_{2}$ were added to each $50 \mathrm{~mL}$ centrifuge tube with concentrations ranging from $0.005 \mathrm{mM}$ to $0.1 \mathrm{mM}$ and brought up to 10 $\mathrm{mL}$ total volume with Milli-Q water. The $\mathrm{pH}$ was adjusted to $6.0 \pm 0.1$ using dilute $\mathrm{HNO}_{3}$ or $\mathrm{NH}_{4} \mathrm{OH}$.

Experimental data was fit to the Langmuir adsorption model, which represents homogeneous adsorption and estimates the adsorption maximum by limiting adsorption to monolayer coverage. The Langmuir adsorption equation applied for analysis is shown in Eq. $2,48,49$

$$
q_{e}=\frac{K_{L} q_{m}\left[\mathrm{M}^{n+}\right]_{\mathrm{eq}}}{1+K_{L}\left[\mathrm{M}^{n+}\right]_{\mathrm{eq}}}
$$

where $q_{e}$ is the mass normalized equilibrium adsorption of the metal for $\mathrm{Mg}^{2+}$ and $\mathrm{Cu}^{2+}$ $(\mu \mathrm{mol} / \mathrm{g}), q_{m}$ is the mass normalized adsorption values for these cations $(\mu \mathrm{mol} / \mathrm{g})$, and $K_{\mathrm{L}}$ 
is the Langmuir constant $(L / \mu \mathrm{mol})$, The Langmuir fitting parameters were estimated by fitting the data using the curve fitting function in Igor Pro. Other experimental details are given in the S.I.

The experimental results are summarized in Fig. 3 depicting the results of competitive adsorption of $\mathrm{Cu}^{2+}$ and $\mathrm{Mg}^{2+}$ on fumed silica surfaces. The background electrolyte was $0.01 \mathrm{M} \mathrm{NH}_{4} \mathrm{NO}_{3}$ at $\mathrm{pH}=6.5$. $\mathrm{Cu}$ has a higher affinity towards silica surface compared to $\mathrm{Mg}$. The adsorption isotherm data is fit with the Langmuir adsorption model in which the adsorption maximum values, $q_{m}$, are $14 \pm 3 \mu \mathrm{mol} / \mathrm{g}$ and $5 \pm 1 \mu \mathrm{mol} / \mathrm{g}$, for $\mathrm{Cu}^{2+}$ and $\mathrm{Mg}^{2+}$, respectively. Likewise, the distribution factors and the resulting separation factor of $\mathrm{Cu}^{2+}$ over $\mathrm{Mg}^{2+}$ maintained values of 4-5 over a large concentration (see the S.I.). Although the experimental surface termination is likely different from the reconstructed $\beta$-cristobalite (001) model used in our AIMD studies, the measurements and modeling consistently show that $\mathrm{Cu}^{2+}$ is more strongly bound. A quantitive comparison is currently impossible because AIMD simulations contain only one $\mathrm{Cu}^{2+}$ that cannot form dimers.

Next we address the static distributions in the protonation state of the $\mathrm{SiOH}$ surface group coordinated to the cation as desorption proceeds. Nearest-neighbor $\mathrm{SiOH}$ groups are $\sim 5 \AA$ apart, and $\mathrm{H}^{+}$exchanges occur via water bridges. For $\mathrm{Na}^{+}$(Fig. 4ha), in sampling windows centered around $Z \sim 2.7 \AA$ and below, the silanol group is deprotonated at the cation binding site. This maximizes electrostatic attraction with $\mathrm{Na}^{+}$. The exception is $Z \sim 1.9 \AA$. A closer examination reveals that the $\mathrm{Na}^{+}$ion is vacillating between two $\mathrm{SiO}^{-} / \mathrm{SiOH}$ groups, coordinating to one and then the other. When $Z$ is around $\sim 3.0$ to $4.0 \AA, P(Z)$ fluctuates between 0.4 and 1.0. Asymptotically, when $\mathrm{Na}^{+}$is infinitely far away, each of the four $\mathrm{SiOH}$ on this surface should have an equal, $25 \%$ probability of being deprotonated. The AIMD trajectories are not sufficiently long to reflect that. We stress that our trajectory lengths are chosen to converge $\Delta W(Z)$ to a certain precision, not necessarily other properties like mean protonation states.

$\mathrm{Mg}^{2+}$ and $\mathrm{Cu}^{2+}$ exhibit qualitatively similar protonation behavior (Fig. 4b,c), despite the fact that their $\Delta W(Z)$ are significantly different; $\mathrm{Cu}^{2+}$ dissociates a $\mathrm{H}_{2} \mathrm{O}$ at large $Z$ while $\mathrm{Mg}^{2+}$ does not; and the error bars in $P(Z)$ may be large. $P(Z) \approx 0$ at $Z<2.4 \AA$ presumably because $\mathrm{M}^{2+}$ strongly repels the like-charged $\mathrm{H}^{+}$in its vicinity. $P(Z) \sim 1$ from 2.4 to $3.3 \AA$ the region between inner- and outer-sphere complexes. It drops to a low value around $3.6 \AA$, then returns to higher average protonated states. For both $\mathrm{Mg}^{2+}$ and $\mathrm{Cu}^{2+}, P(Z)$ 


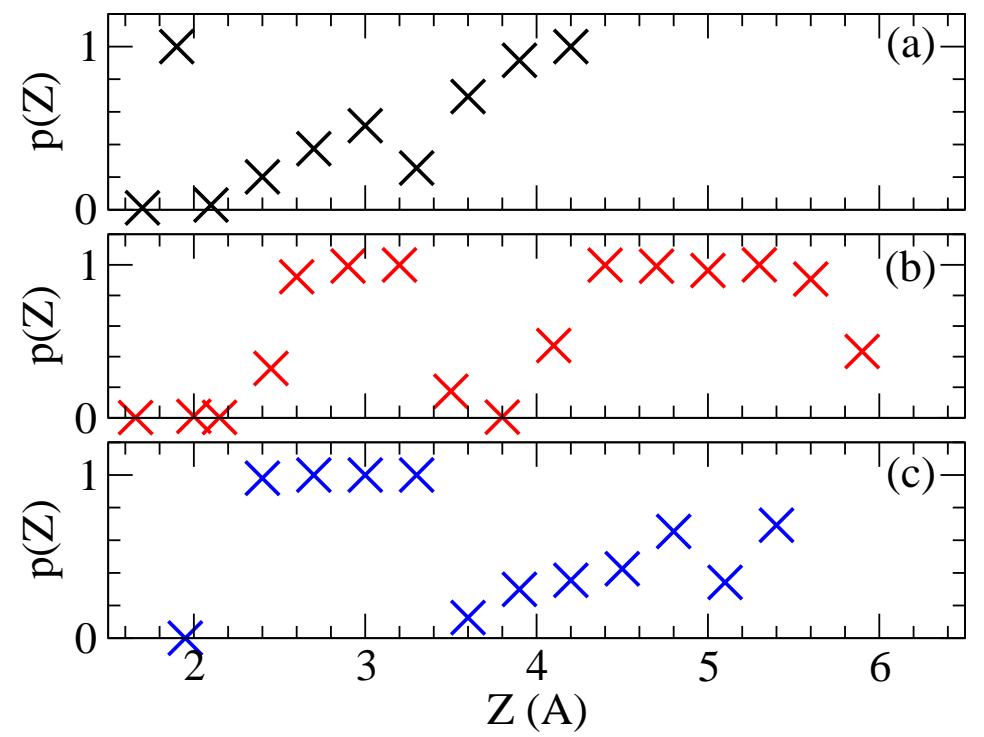

FIG. 4: Protonation states $(p(Z))$ of $\mathrm{SiO}^{-}$group originally bonded to $\mathrm{M}^{n+}$, as a function of sampling window $Z$. (a) $\mathrm{Na}^{+}$; (b) $\mathrm{Mg}^{2+}$; (c) $\mathrm{Cu}^{2+}$. The $\mathrm{SiO}^{-}$is "protonated" if its $\mathrm{O}^{-}$ion is within $1.25 \AA$ of any proton in the simulation cell.

varies non-monotonically as the cation desorbs. This may be a useful consideration when defining the $\mathrm{SiOH}$ protonation as a "slow variable" in future metadynamics ion desorption calculations.

The SI considers dynamic correlations between $\mathrm{SiOH}$ protonation states and $\Delta W(Z)$. We conclude that $\mathrm{SiOH}$ protonation state fluctuations are not strongly dynamically correlated with cation desorption free energies in windows where $0<P(Z)<1$. This suggests that AIMD PMF predictions are reliable despite the somewhat slow $p(t)$ fluctuation time scales.

In conclusion, we have used ab initio molecular dynamics potential-of-mean-force techniques to calculate the desorption free energies of $\mathrm{Na}^{+}, \mathrm{Mg}^{2+}$, and $\mathrm{Cu}^{2+}$ from a model silica surface with a $4.0 / \mathrm{nm}^{2} \mathrm{SiOH}$ surface density and $\mathrm{pK}_{a} \sim 7.0-8.1$. The cations are initially adsorbed in an inner-sphere monodentate manner. $\mathrm{Na}^{+}$at standard state $(1.0 \mathrm{M}$ concentration) is predicted to be unbound, while the divalent cations are predicted to be thermodynamically stable when coordinated to $\mathrm{SiO}^{-}$groups by 0.14 and $0.47 \mathrm{eV}$, respectively, in inner-sphere configurations. The predicted trends are in qualitative agreement with competitive batch adsorption measurements. We argue that negatively charged surfaces which allow bi- or tri-dentate $\mathrm{SiO}^{-}$binding to metal ions should favor inner-sphere 
adsorption over outer-sphere adsorption even more strongly. Water-bridge-assisted proton exchange between surface $\mathrm{SiOH}$ groups is observed as cation desorption proceeds, which increases interfacial fluctuations. The protonation state $(P(Z))$ of the $\mathrm{SiO}^{-}$group at the binding site is not a monotonic function of the separation $Z$ between the cation and the surface. A water molecular coordinated to $\mathrm{Cu}^{2+}$ donates a proton to surface $\mathrm{SiO}^{-}$with predicted $\mathrm{pK}_{a}$ of about 7.0-8.1,, 33 forming 4-coordinated $\mathrm{Cu}^{2+}\left(\mathrm{OH}^{-}\right)\left(\mathrm{H}_{2} \mathrm{O}\right)_{3}$ complexes. To within computational accuracy, this is consistent with the experimental $\mathrm{Cu}^{2+}\left(\mathrm{H}_{2} \mathrm{O}\right)_{6} \mathrm{pK}_{a}$ of about 8. In contrast, $\mathrm{Mg}^{2+}$ invariably forms octahedral $\mathrm{Mg}^{2+}\left(\mathrm{H}_{2} \mathrm{O}\right)_{6}$ or $\mathrm{Mg}^{2+}\left(\mathrm{H}_{2} \mathrm{O}\right)_{5}\left(\mathrm{SiO}^{-}\right)$ complexes. Our conclusion that the $\mathrm{Cu}^{2+} \mathrm{OH}^{-}$complexes occur as $\mathrm{Cu}^{2+}$ desorbs also informs speciation choices for future classical-MD investigations. While AIMD is computationally costly, our predictions will be useful for benchmarking and assessing the applicability of simpler molecular force fields for ion-binding application, and paves the way for enumerating desorption free energies from multiple binding sites in the future.

Supporting Information Available: Details of PMF calculations; snapshots of cation adsorption on silica surfaces and classical PMF results conducted using classical force fieldbased molecular dynamics; details of batch adsorption measurements; dynamical correlations between $\mathrm{SiOH}$ protonation state and cation desorption

We thank Jessica Rimsza and Jacob Harvey for useful discussions. Sandia National Laboratories is a multimission laboratory managed and operated by National Technology and Engineering Solutions of Sandia, LLC, a wholly owned subsidiary of Honeywell International, Inc., for the U.S. Department of Energys National Nuclear Security Administration under contract de-na0003525. This work is based on materials support by the U.S. DOE Office of Basic Energy Sciences, Division of Chemical Sciences, Geosciences, and Biosciences.

1 DeWalt-Kerian, E.L.; Kim, S. Azam, M.S.; Zeng, H.; Liu, Q.; Gibbs, J.M. pH-dependent Inversion of Hofmeister Trends in the Water Structure of the Electric Double Layer. J. Phys. Chem. Lett. 2017, 8, 2855-2861.

2 Shen, Z.; Kerisit, S.N.; Stack, A.G.; Rosso, K.M. Free-energy Landscape of the Dissolution of Gibbsite at High pH. J. Phys. Chem. Lett. 2018, 9, 1809-1814.

3 Peng, Q.M.; Guo, J.X.; Zhang, Q.R.; Xiang, J.Y.; Liu, B.Z.; Zhou, A.G.; Liu, R.P.; Tian, Y.T. 
Unique Lead Adsorption Behavior of Activated Hydroxyl Group in Two-Dimensional Titanium Carbide. J. Am. Chem. Soc. 2014, 136, 4113-4116.

4 Hayes, K.F.; Roe, A.L.; Brown, G.E.; Hodgson, K.O., Leckie, J.O.; Parks, G.A. In Situ X-Ray Adsorption Study of Surface Complexes - Selenium Oxyanions on $\alpha$-FeOOH. Science 1987, 238, 783-786.

5 Nihonyanagi, S.; Yamaguchi, S.; Tahara, T. Counterion Effect on Interfacial Water at Charged Interfaces and its Relevance to the Hofmeister Series. J. Am. Chem. Soc. 2014, 136, 6155-6158.

6 Sverjensky, D.A. Prediction of the Speciation of Alkaline Earths Adsorbed on Mineral Surfaces in Salt Solutions. Geochim. Cosmochim. Acta 2006, 70, 2427-2453.

7 Leung, K.; Criscenti, L.J. Lead and Selenite Adsorption at Water-Goethite Interfaces from First Principles. J. Phys. Condens. Matter 2017, 29, 365101, and references therein.

8 Hayes, P.L.; Malin, J.N.; Jordan, D.S.; Geiger, F.M. Get charged up: Nonlinear Optical Voltammetry for Quantifying the Thermodynamics and Electrostatics of Metal Cations at Aqueous/Oxide Interfaces. Chem. Phys. Lett. 2010, 499, 183-192.

9 Kerisit, S.; Zarzycki, P.; Rosso, K.M. Computational Molecular Simulation of the Oxidative Adsorption of Ferrous Iron at the Hematite (001)-Water Interface. J. Phys. Chem. C 2015, $119,9242-9252$.

10 Kim, Y.; Kirkpatrick, R.J. ${ }^{23} \mathrm{Na}$ and ${ }^{133} \mathrm{Cs}$ NMR Study of Cation Adsorption on Mineral Surfaces: Local Environments, Dynamics, and Effects of Mixed Cations. Geochim. Cosmochim. Acta 1997, 61, 5199-5208.

11 Cheah, S.-F.; Brown, G.E.; Parks, G.A. XAFS Study of $\mathrm{Cu}$ Model Compounds and $\mathrm{Cu}^{2+}$ Sorption Products on Amorphous $\mathrm{SiO}_{2}, \gamma-\mathrm{Al}_{2} \mathrm{O}_{3}$, and Anatase. Amer. Mineral. 2000, 85, 118132.

12 Cheah, S.F.; Brown, G.E. Jr.; Parks, G.A. XAFS Spectroscopy Study of Cu(II) Sorption on Amorphous $\mathrm{SiO}_{2}$ and $\gamma-\mathrm{Al}_{2} \mathrm{O}_{3}$ : Effects of Substrate and Time on Sorption Complexes. J. Coll. Interface Sci. 1998, 208, 110-128.

13 Cheah, S.F.; Brown, G.E. Jr.; Parks, G.A. The Effect of Substrate Type and 2,2'-Bipyridine on the Sorption of Copper(II) on Silica and Alumina. Voigt, J.A., Wood, T.E., Bunker, B.C., Casey, W.H., Crossey, L.J. (Eds.), Mater. Res. Soc. Proc. 1997, 432, 231-236.

14 Elliot, H.A., Liberati, M.R.; Huang, C.P. Competitive Adsorption of Heavy Metals by Soils. J. Envir. Quality 1986, 15, 214-219. 
15 Subramaniam, K.; Vithayaveroj, V.; Yiacoumi, S.; Tsouris, C. Copper Uptake by Silica and Iron Oxide under High Surface Coverage Conditions: Surface Charge and Sorption Equilibrium Modeling. J. Coll. Interface Sci. 2003, 268, 12-22.

16 Allen, M.; Machesky, M.L.; Wesolowski, D.J.; Kabengi, N. Calorimetric Study of Alkali and Alkaline-Earth Cation Adsorption and Exchange at the Quartz-Solution Interface. J. Coll. Interface Sci. 2017, 504, 538-548.

17 Hocine, S.; Hartkamp, R.; Siboulet, B.; Duvail, M.; Coasne, B.; Turq, P.; Dufreche, J.-F. How Ion Condensation Occurs at a Charged Surface: a Molecular Dynamics Investigation of the Stern layer for Water-Silica Interfaces. J. Phys. Chem. C 2016, 120, 963-973.

18 Katz, L.E.; Criscenti, L.J.; Chen, C.-C.; Larentzos, J.P.; Liljestrand, H.M. Temperature Effects on Alkaline Earth Metal Ions Adsorption on Gibbsite: Approaches from Macroscopic Sorption Experiments and Molecular Dynamics Simulations. J. Coll. Interface Sci. 2013, 399, 68-76.

19 Hartkamp, R.; Siboulet, B.; Dufreche, J.F.; Coasne, B. Ion-Specfic Adsorption and Electroosmosis in Charged Amorphous Porous Silica. Phys. Chem. Chem. Phys. 2015, 17, 24683-24695.

20 Loganathan, N.; Kalinichev, A.G. Quantifying the Mechanisms of Site-Specific Ion Exchange at an Inhomogeneously Charged Surface: Case of $\mathrm{Cs}+/ \mathrm{K}+$ on Hydrated Muscovite Mica. J. Phys. Chem. C 2017, 121, 7829-7836.

21 Fogarty, J.C.; Aktulga, H.M.; Grama, A.Y.; Van Duin, A.C.; Pandit, S.A. A Reactive Molecular Dynamics Simulation of the Silica-Water Interface. J. Chem. Phys. 2010, 132, 174704.

22 Mahadevan, T.S.; Garofalini, S.H. Dissociative Water Potential for Molecular Dynamics Simulations. J. Phys. Chem. B 2007, 111, 8919-8927.

23 Rimsza, J.M.; Jones, R.E.; Criscenti, L.J. Interaction of $\mathrm{NaOH}$ Solutions with Silica Surfaces. J. Coll. Interface. Sci. 2018, 516, 128-137.

24 Liu, X.; Cheng, J.; Sprik M.; Lu, X.C.; Wang, R. Understanding Surface Acidity of Gibbsite with First Principles Molecular Dynamics Simulations. Geochim. Cosmochim. Acta, 2013, 120, 487-495.

25 Churakov, S.V.; Labbez, C.; Pegado, L.; Sulpizi, M. Intrinsic wcidity of Surface Sites in Calcium Silicate Hydrates and its Implication to their Electrokinetic Properties. J. Phys. Chem. C 2014, $118,11752-11762$.

26 Pfeiffer-Laplaud, M.; Gaigeot, M.-P.; Sulpizi, M. pk(a) at Quartz/Electrolyte Interfaces. J. Phys Chem. Lett. 2016, 7, 3229-3234. 
27 Pfeiffer-Laplaud M.; Gaigeot, M.-P. Electrolytes at the Hydroxylated (0001) $\alpha$-Quartz/Water Interface: Location and Structural Effects on Interfacial Silanols by DFT-based MD. J. Phys Chem. C 2016, 120, 14034-14047.

28 Pfeiffer-Laplaud, M.; Gaigeot, M.-P. Adsorption of Singly Charged Ions at the Hydroxylated (0001) $\alpha$-Quartz/Water Interface. J. Phys Chem. C 2016, 120, 4866-4880.

29 Pfeiffer-Laplaud, M.; Costa, D.; Tielens, F.; Gaigeot, M.-P.; Sulpizi, M. Bimodal Acidity at the Amorphous Silica/Water Interface. J. Phys Chem. C 2015, 119, 27354-27362.

30 Tazi, S.; Rotenberg, B.; Salanne, M.; Sprik, M.; Sulpizi, M. Absolute Acidity of Clay Edge Sites from Ab-Initio Simulations. Geochim. Cosmochim. Acta 2012, 94, 1-11.

31 Sulpizi, M.; Gaigeot, M.-P.; Sprik, M. The Silica-Water Interface: How the Silanols Determine the Surface Acidity and Modulate the Water Properties. J. Chem. Theor. Comput. 2012, 8 $1037-1047$

32 Cheng, J.; Sulpizi, M.; Sprik, M. Redox Potentials and pK(a) for Benzoquinone from Density Functional Theory Based Molecular Dynamics. J. Chem. Phys. 2009, 131, 154504.

33 Leung, K; Nielsen, I.M.B.; Criscenti, L.J. Elucidating the Bimodal Acid-Base Behavior of the Water-Silica Interface from First Principles. J. Am. Chem. Soc., 2009, 131, 18358-18365.

34 Leung, K.; Criscenti, L.J. Predicting the Acidity Constant of a Goethite Hydroxyl Group From First Principles. J. Phys. Condens. Matter 2012, 24, 124015.

35 Dellostritto, M.J.; Kubicki, J.D.; Sofo, J.O. Effect of Ions on H-Bond Structure and Dynamics at the Quartz(101)-Water Interface. Langmuir, 2016, 32, 11353-11365.

36 Zhang, C.; Liu, X.; Lu, X.; Meijer, E.J.; Wang, K.; He, M.; Wang, R. Cadmium(II) Complexes Adsorbed on Clay Edge Surfaces: Insight from First Principles Molecular Dynamics Simulations. Clays and Clay Minerals, 2016, 64, 337-347.

37 Zhang, C.; Liu, X.; Lu, X.; He, M.; Meijer, E.J.; Wang, R. Surface Complexation of Heavy Metal Cations on Clay Edges: Insights from First Principles Molecular Dynamics Simulation of Ni(II). Geochim. Cosmochim. Acta 2017, 203, 54-68.

38 Brinker, C.J.; Scherer, G.W. Sol-Gel Science; Academic Press, London, 1990, Ch. 10.

39 Perdew, J.P.; Burke, K.; Ernzerhof, M. Generalized Gradient Approximation Made Simple. Phys. Rev. Lett. 1996, 777, 3865-3868.

40 Kresse, G.; Joubert, J. From Ultrasoft Pseudopotentials to the Projector Augmented-Wave Method. Phys. Rev. B 1999, 59, 1758-1775. 
41 Kresse, G.; Furthmüller, J. Efficient Iterative Schemes for Ab Initio Total-Energy Calculations Using a Plane-Wave Basis Set. Phys. Rev. B 1996, 54, 11169.

42 Shen Y.R.; Ostroverkhov, V. Sum-Frequency Vibrational Spectroscopy on Water Interfaces: Polar Orientation of Water Molecules at Interfaces. Chem. Rev. 2006, 106, 1140-1154.

43 Darlington, A.M.; Gibbs-Davis, J. Bimodal or Trimodal? The Influence of Starting pH on Site Identity and Distribution at the Low Salt Aqueous/Silica Interface. J. Phys. Chem. C 2015, $119,16560-16567$.

44 Blumberger, J.; Klein, M.L. Revisiting the Free Energy Profile for the Nucleophilic Attack of Hydroxide on Formamide in Aqueous Solution. Chem. Phys. Lett. 2006, 422, 210-217.

45 Pasquarello, A.; Petri, I.; Salmon, P.S.; Parisel, O.; Car, R.; Toth, E.; Powell, D.H.; Fischer, H.E.; Helm, L.; Merbach, A.E. First Solvation Shell of the $\mathrm{Cu}(\mathrm{II})$ Aqua Ion: Evidence for Fivefold Coordination. Science, 2001, 291, 856-859.

46 Rowley, C.N.; Roux, B. The Solvation Structure of $\mathrm{Na}^{+}$and $\mathrm{K}^{+}$in Liquid Water Determined from High Level ab initio Molecular Dynamics Simulations. J. Chem. Theory Comput. 2012, 8, 3526-3535.

47 Grossfield, A.; Ren, P.; Ponder, J.W. Ion Solvation Thermodynamics from Simulation with a Polarizable Force Field. J. Am. Chem. Soc. 2003, 125, 15671-15682.

48 Langmuir, I. The Adsorption of Gases on Plane Surfaces of Glass, Mica and Platinum. J. Am. Chem. Soc. 1918, 40, 1361-1403.

49 Mahmoud, M.A. Kinetics and Thermodynamics of Aluminum Oxide Nanopowder Adsorbent for Fe(III) from Aqueous Solutions. Beni-Suef Univ. J. Basic Applied Sci. 2015, 4, 142-149.

50 Stumm, W.; Morgan, J.J. Aquatic Chemistry: Chemical Equilibria and Rates in Natural Waters, 3rd ed.; John Wiley \& Sons: New York, 1996.

51 Baes, C.F.; Mesmer, R.E. Hydrolysis of Cations, Krieger Publishing Company: Malabar, FL, 1976.

52 Jackson, V.E.; Felmy, A.R.; Dixon, D.A. Prediction of the $\mathrm{pK}_{a}$ 's of Aqueous Metal Ion +2 Complexes. J. Phys. Chem. A 2015, 119, 2926-2939.

53 Langmuir, D. Aqueous Environmental Geochemistry 1997 (Prentice, New Jersey) 


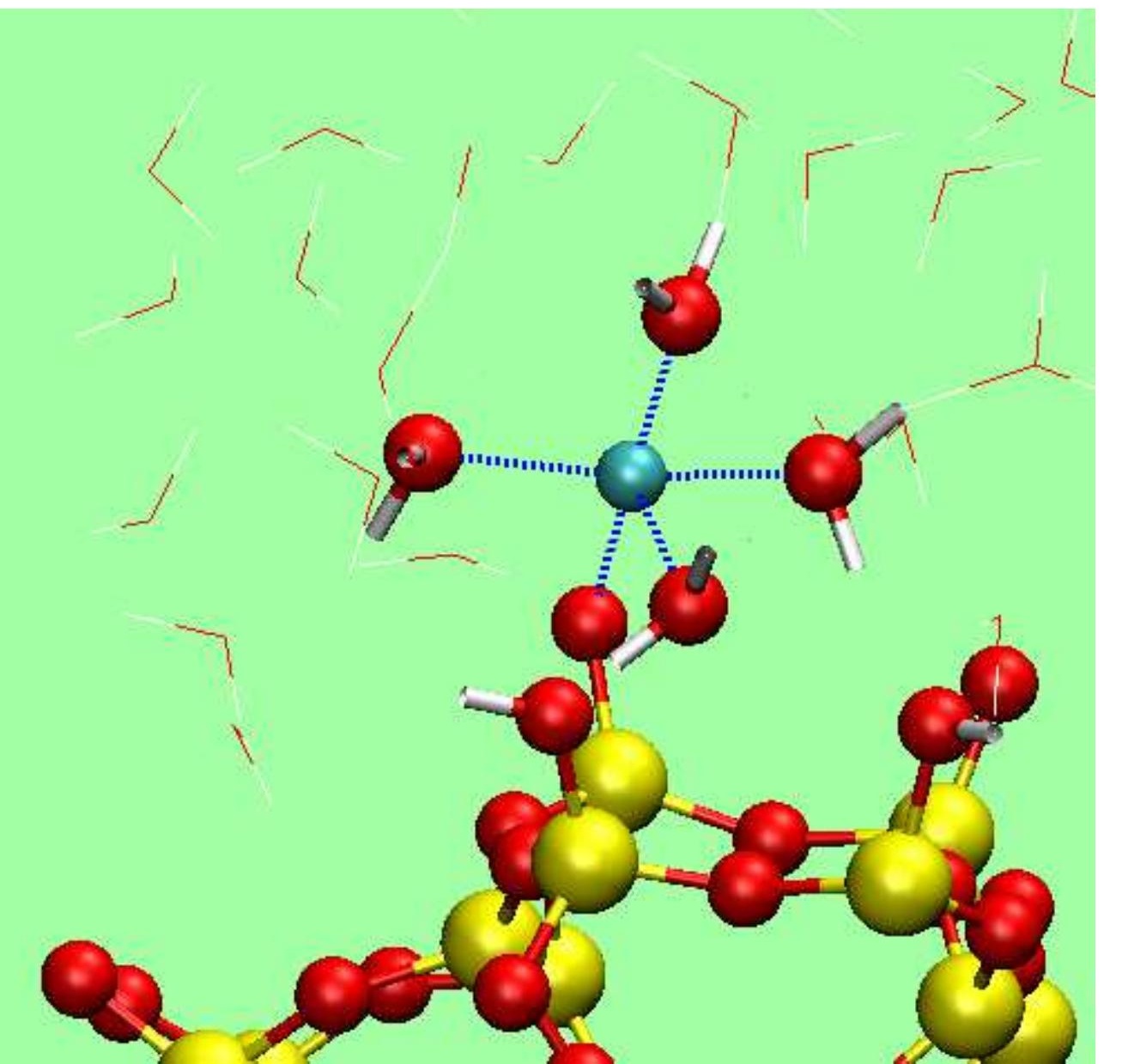

